\title{
Clinical Biomarkers and Prognosis in Taiwanese Patients with Non-Small Cell Lung Cancer (NSCLC)
}

\author{
Yixia Li ${ }^{1}$, Yea-Jyh Chen ${ }^{2}$, Li-Jung Chang ${ }^{3}$, Michael Hendryx ${ }^{1,4}$, Juhua Luo ${ }^{1,4,5^{*}}$ \\ ${ }^{1}$ Department of Community Medicine, School of Medicine, West Virginia University, Morgantown, USA; ${ }^{2}$ School of Nursing, West \\ Virginia University, Morgantown, USA; ${ }^{3}$ Department of Nursing, Tzu Chi College of Technology, Hualien, Taiwan; ${ }^{4}$ West Virginia \\ Rural Health Research Center, Morgantown, USA; ${ }^{5}$ Mary Babb Randolph Cancer Center, West Virginia University, Morgantown, \\ USA. \\ Email: ${ }^{*}$ jiluo@hsc.wvu.edu
}

Received May $9^{\text {th }}, 2012$; revised June $11^{\text {th }}, 2012$; accepted June $30^{\text {th }}, 2012$

\begin{abstract}
Introduction: Lung cancer is the leading cause of cancer death worldwide with poor survival rates. However, the prognostic factors for survival of patients with lung cancer are not well-established. In this study, we examined the impact of routine laboratory biomarkers and traditional factors on survival of patients with non-small cell lung cancer (NSCLC). Method: Secondary data analysis was conducted from a retrospective study of 404 patients with newly diagnosed lung cancer in 2005-2007 in Taiwan. There were eight routine laboratory biomarkers and eight traditional factors investigated in the analyses. Cox proportional hazards model was used to assess the hazard ratios for the association between risk factors and patient overall survival. The Kaplan-Meier method was used to compare survival curves for each prognostic indicator. Results: High WBC counts (HR $=1.798,95 \%$ CI: $1.225-2.639)$, low Hgb level $(\mathrm{HR}=1.437,95 \% \mathrm{CI}$ : $1.085-1.903)$, and low serum albumin level $(\mathrm{HR}=2.049,95 \% \mathrm{CI}: 1.376-3.052)$ were significant laboratory prognostic biomarkers for poor NSCLC survival. Additionally we confirmed the traditional prognostic factors for poor overall survival among NSCLC patients, including older age, comorbidity conditions, advanced cancer stage, and non-surgical treatment. Conclusions: This study identified three available laboratory biomarkers, high WBC counts, low Hgb level, and low serum albumin level, to be significant prognostic factors for poorer overall survival in NSCLC patients. Further prognostic evaluation studies are warranted to compare different ethnic groups on the prognostic values of these clinical parameters in NSCLC survival outcomes. These identified prognostic biomarkers should be included in early risk screening of hospitalized lung cancer patient population.
\end{abstract}

Keywords: Clinical Biomarkers; Non-Small Cell Lung Cancer (NSCLC); Prognostic Factors

\section{Introduction}

Lung cancer is the leading cause of cancer death worldwide [1]. An estimated 1.6 million new cases of lung cancer occurred worldwide in 2008, accounting for about $13 \%$ of total cancer diagnoses [2]; and an estimated 951,000 men and 427,400 women died from the disease worldwide in 2008. Histologically, lung cancer can be classified into two types: small cell lung cancer (SCLC) and non-small cell lung cancer (NSCLC). NSCLC accounts for $85 \%$ of lung cancer cases, and approximately $65 \%$ of patients with NSCLC present with advancedstage (III or IV) disease [3]. In addition, lung cancer is predominantly a disease of elderly people: the median age of newly diagnosed lung cancer patients is approximately 68 years and as many as $40 \%$ of patients are older than 70 years [4]. The five-year survival rates among

${ }^{*}$ Corresponding author. patients with NSCLC after complete resection are $46 \%$ $81 \%$ with stage IA to IIB, compared to $21 \%-24 \%$ with stage IIIA to IV [5]. Furthermore, overall survival among patients receiving chemotherapy also remains poor with a median 4 to 15 monthssurvival time [6]. Therefore, studying prognostic biomarkersas survival predictors may contribute toimproveddisease prognosis and treatment guidelines for lung cancer.

Prognostic predictors for lung cancer outcomes are inconsistent in previous literature. The most widely accepted prognostic factors for patients with NSCLC include tumor stage, performance status, and weight loss [7-12]. Besides these factors, biochemical or hematologic markers, such as white blood cell (WBC) counts, neutrophil counts and hemoglobin ( $\mathrm{Hgb})$ level, are also associated with NSCLC survival. A previous study performed by the North Central Cancer Treatment Group (NCCTG), which included 1053 lung cancer patients, 
revealed that patients who had high WBC counts and low $\mathrm{Hgb}$ levels had significantly worse survival than their counterparts [13]. However, the prognostic importance of complete blood count findings were inconsistent with other studies [14-18] where no significant association was found for WBC counts or Hgb level. In addition, neutrophil counts in a study by Ferrigno et al. were found to independently predict the survival of NSCLC patients [19]. Similar to Ferrigno's result, the European Lung Cancer Working Group found that a high-neutrophil count was an independent prognostic factor for poor survival in patients with unresectable advanced NSCLC [20]. Paddisonalso reported that high level neutrophil counts and low Hgblevel predicted poor survival of NSCLC patients [21]. Furthermore, another studyfound that platelet countswere associated with poor overall survival in aunivariate model but werenot significant in multivariate analysis [22].

There may be additional biochemical markers related to lung cancer survival, such as serum albumin level and serum sodium level. Serum albumin level, a nutritional indicator, has been examined as a prognostic lung cancer marker among both SCLC and NSCLC patients in several previous studies $[12,23,24]$. Maeda et al. observed that serum albumin level was one of the most significant prognostic factors for advanced NSCLC in both univariate and multivariate analysis [12]. In Win's study, serum albumin level was identified to be a significant prognostic factor in univariatemodelbut not inmultivariable analysis for lung cancer patients [23]. A similar association between serum albumin level and lung cancer survival was observed by Tas et al. [24]. In addition, abnormal serum sodium level has been studied asa poor survival predictor for lung cancer. Previous research has reported thathyponatremia predicts poor survival of SCLC patients [15,25-27], but there appears to be no previous research onhyponatremiain relation to NSCLC survival outcome.

Because of incomplete and in some cases inconsistent evidence on prognostic biomarkers for NSCLC survival, the aim of this study was to examine the relationships between routine laboratory parameters including WBC counts, neutrophil percentage, lymphocyte percentage, Hgblevel, platelet counts, serum albumin level, and serum sodium level on overall survival in NSCLC patients.

\section{Materials and Methods}

\subsection{Study Design and Measures}

This study is a secondary data analysis derived froma retrospective study of patients with newly diagnosed lung cancer in the years 2005-2007 in Taiwan. Detailed description of this study sample design and methods are available in Luo et al. [28]. In brief, the retrospective study screened potential patients through hospital medi- cal records. Eligible patients were selected based on initial hospitalization with lung cancer as the primary diagnosis, who were discharged to home and were older than 40 years old. There were 404 patients eligible in the study for final analysis.

Patients' characteristics, extracted from hospital records, include age, gender, the Eastern Cooperative Oncology Group (ECOG) performance (PS) (0 - 5 with 0 denoting perfect health and 5 denoting death) [29], smoking status (never, former, current), body mass index (BMI; $\mathrm{kg} / \mathrm{m}^{2}$ ), Charlson comorbidity Index (CCI; excluded lung cancer as the primary disease), tumor stage (less advanced — stage I, II and IIIA and advanced—stage IIIB and IV), cancer treatment (surgery with/without one or more types of supportive care [e.g. chemotherapy, radiation, tyrosin kinase inhibitor targeted therapy], chemotherapy with/without other supportive care, or no cancer treatment). The CCI, a weighted index score with a possible range of $0-35$, wasused to evaluate patients' comorbid conditions according to the influence of comorbidity on overall mortality risk [30,31]. The patients' BMI was calculated and classified into four categories: underweight $\left(<18.5 \mathrm{~kg} / \mathrm{m}^{2}\right)$, normal $\left(18.5-<25 \mathrm{~kg} / \mathrm{m}^{2}\right)$, overweight $\left(25-<30 \mathrm{~kg} / \mathrm{m}^{2}\right)$ and obese $\left(>=30 \mathrm{~kg} / \mathrm{m}^{2}\right)$. Laboratory data including WBC counts, Hgb level, neutrophil percentage, lymphocyte percentage, platelet counts, monocyte percentage, serum albumin level, and serum sodium level were measured at the index visit. These variables were considered as the main prognostic factors of interest for the study. We used the admission or first-time measure if more than one set of laboratory biomarkers were examined during the index visit. In order not to lose study power, we kept patients with missing data in the final analysis and categorized those patients as an additional group. The outcome of interest in this study was survival duration, which was defined as the interval in months from the discharge date of the index visit to death from any cause. Patients' survival data were followed through cancer registry records until the end of 2010.

\subsection{Statistical Analysis}

We categorized all potential prognostic variables including WBC counts, Hgb level, neutrophil percentage, lymphocyte percentage, platelet counts, monocyte percentage, albumin level, and sodium level into normal and abnormal values according to standard laboratory norms (cutpoints are listed in Table 1) [32]. For sodium level, we divided it into two groups since therewas only one patient with sodium level higher than $145(\mathrm{mmol} / \mathrm{l})$.

For univariate analyses, we estimated survival curves using the Kaplan-Meier method and compared these curves by the log-rank test. Survival duration was also estimated by fitting the data with a Cox regression model [33]. All variables reaching statistical significance $(\mathrm{p}<$ 
Table 1. Characteristics of lung cancer patients during the study follow-up $(\mathrm{N}=404)$.

\begin{tabular}{|c|c|c|c|}
\hline Variable & No. $(\%)$ & Death within follow-up (N) & Death within follow-up (\%) \\
\hline \multicolumn{4}{|l|}{ Age (years) } \\
\hline$<70$ & $201(49.75)$ & 167 & 83.08 \\
\hline$\geq 70$ & $203(50.25)$ & 185 & 91.13 \\
\hline \multicolumn{4}{|l|}{ Gender } \\
\hline Female & $148(36.63)$ & 124 & 83.78 \\
\hline Male & $256(63.37)$ & 228 & 89.06 \\
\hline \multicolumn{4}{|l|}{ Smoking status } \\
\hline Never & $179(44.31)$ & 149 & 83.24 \\
\hline Former & $156(38.61)$ & 141 & 90.38 \\
\hline Current & $69(17.08)$ & 62 & 89.86 \\
\hline \multicolumn{4}{|l|}{ ECOG Performance status } \\
\hline$<2$ & $264(65.35)$ & 217 & 82.20 \\
\hline$\geq 2$ & $140(34.65)$ & 135 & 96.43 \\
\hline \multicolumn{4}{|l|}{ BMI $\left(\mathrm{kg} / \mathrm{m}^{2}\right)$} \\
\hline$<18.5$ & $39(9.65)$ & 36 & 92.31 \\
\hline $18.5-<25$ & $225(55.69)$ & 193 & 85.78 \\
\hline $25-<30$ & $86(21.29)$ & 70 & 81.40 \\
\hline$\geq 30$ & $13(3.22)$ & 12 & 92.31 \\
\hline Missing & $41(10.15)$ & 41 & 100.00 \\
\hline \multicolumn{4}{|l|}{ Co-morbidity score } \\
\hline$<4$ & $136(33.66)$ & 105 & 77.21 \\
\hline $4-8$ & $200(49.50)$ & 184 & 92.00 \\
\hline$\geq 8$ & $68(16.83)$ & 63 & 92.65 \\
\hline \multicolumn{4}{|l|}{ Cancer stage } \\
\hline Less advanced & $41(10.15)$ & 25 & 60.98 \\
\hline Advanced & $363(89.85)$ & 327 & 90.08 \\
\hline \multicolumn{4}{|l|}{ Cancer treatment } \\
\hline Surgery & $24(5.94)$ & 8 & 33.33 \\
\hline Chemotherapy and /or other supportive care & $300(74.26)$ & 268 & 89.33 \\
\hline None & $80(19.80)$ & 76 & 95.00 \\
\hline \multicolumn{4}{|l|}{ WBC counts $\left(10^{3} / \mu \mathrm{L}\right)$} \\
\hline$\leq 5.5$ & $63(15.59)$ & 52 & 82.54 \\
\hline $5.5-15.5$ & $300(74.26)$ & 260 & 86.67 \\
\hline$>15.5$ & $41(10.15)$ & 40 & 97.56 \\
\hline \multicolumn{4}{|l|}{ Neutrophil (\%) } \\
\hline $27-55$ & $35(8.66)$ & 25 & 71.43 \\
\hline$>55$ & $339(83.91)$ & 299 & 88.20 \\
\hline Missing & $30(7.43)$ & 28 & 93.33 \\
\hline \multicolumn{4}{|l|}{ Lymphocyte (\%) } \\
\hline$<16$ & $175(43.32)$ & 162 & 92.57 \\
\hline $16-46$ & $220(54.46)$ & 187 & 85.00 \\
\hline$>46$ & $9(2.23)$ & 3 & 33.33 \\
\hline
\end{tabular}




\begin{tabular}{|c|c|c|c|}
\hline \multicolumn{4}{|l|}{ Continued } \\
\hline \multicolumn{4}{|c|}{ Hemoglobin (g/dL) } \\
\hline$<11.5$ & $122(30.20)$ & 118 & 96.72 \\
\hline $11.5-13.5$ & $152(37.62)$ & 129 & 84.87 \\
\hline$>13.5$ & $130(32.18)$ & 105 & 80.77 \\
\hline \multicolumn{4}{|c|}{ Platelet counts $(\mathrm{Thou} / \mu \mathrm{l})$} \\
\hline$<150$ & $157(38.86)$ & 133 & 84.71 \\
\hline $150-400$ & $164(40.59)$ & 144 & 87.80 \\
\hline$>400$ & $51(12.62)$ & 48 & 94.12 \\
\hline Missing & $32(7.92)$ & 27 & 84.38 \\
\hline \multicolumn{4}{|c|}{ Monocyte (\%) } \\
\hline$<4$ & $99(24.50)$ & 85 & 85.86 \\
\hline $4-11$ & $280(69.31)$ & 243 & 86.79 \\
\hline$>11$ & $25(6.19)$ & 24 & 96.00 \\
\hline \multicolumn{4}{|c|}{ Albumin (g/dl) } \\
\hline$<3.1$ & $40(9.90)$ & 40 & 100.00 \\
\hline $3.1-4.3$ & $175(43.32)$ & 151 & 86.29 \\
\hline$>4.3$ & $28(6.93)$ & 20 & 71.43 \\
\hline missing & $161(39.85)$ & 141 & 87.58 \\
\hline \multicolumn{4}{|c|}{ Sodium (mmol/l) } \\
\hline$<136$ & $189(46.78)$ & 177 & 93.65 \\
\hline $136-147$ & $215(53.22)$ & 175 & 81.40 \\
\hline
\end{tabular}

0.05 ) at the univariate level were included in the multivariate analysis. We performed Pearson correlations among the selected variables for collinearity before the multivariate analysis. If any two variables were highly correlated ( $r>0.6)$, only one was selected in the multivariate model. We used the Cox proportional hazards model to perform the multivariate analysis to adjust for all included variables. The hazard ratios were calculated to assess the death risk for various prognostic factors. All statistical analyses were done using SAS version 9.2 with a significant $\mathrm{p}$-value criterion of 0.05 or less.

\section{Results}

\subsection{Baseline Patient Characteristics}

Of the total 404 patients with newly diagnosed NSCLC, the median follow-up duration time was 10.7 months (range, 0 - 70 months). Mean age of the study sample population was 67.6 years $(\mathrm{SD}=11.0)$. Over $60 \%$ of the patients $(\mathrm{N}=256)$ were male; approximately $39 \%$ of patients were former smokers and $17 \%$ were current smokers. The majority of patients $(90 \%)$ were diagnosed at an advanced stage (stage IIIB or stage IV). Overall, 352 patients $(87 \%)$ died by the end of 2010. Table 1 summarizes the study patient characteristics.

\subsection{Univariate Analysis}

Univariate analysis revealed the following patient characteristics to be significant prognostic factors for poor survival: older age ( $\geq 70$ years), male, current smoker, poor performance status (PS $\geq 2)$, low BMI $(\leq 18.5$ $\mathrm{kg} / \mathrm{m}^{2}$ ), high CCI score ( $\left.\geq 4\right)$, advanced cancer stage (IIIB and IV), cancer treatment (chemotherapy with/without other supportive cancer treatment or no cancer treatment), high WBC $\left(>15.5 \times 10^{3} / \mu \mathrm{L}\right)$, high neutrophil percentage $(>55 \%)$, lower $(<16 \%) /$ higher $(>46 \%)$ lymphocyte percentage, low Hgblevel $(<11.5 \mathrm{~g} / \mathrm{dl})$, lower $(<3.1 \mathrm{~g} / \mathrm{dl}) /$ higher $(>4.3 \mathrm{~g} / \mathrm{dl})$ albumin level, and low sodium level $(<136 \mathrm{mmol} / \mathrm{l})$. Other variables, including platelet counts and monocyte percentage were not observed to be significantly associated with overall NSCLC survival ( $\mathrm{p}>$ 0.05; see Table 2).

In patients with advanced cancer stage, the median survival time was 10.1 (95\%CI: 8.6 - 12.0) months compared with 26.2 survival months among those patients with less advanced stage $(p<0.0001)$. In patients with high WBC counts, the median survival was $1.93(95 \% \mathrm{CI}$ : 1.1 - 4.1) months, compared with the patients with normal and low WBC counts (11.9 vs 14.3 survival months, respectively; $p<0.0001$ ). Similarly, patients with low 
Table 2. Univariate analyses of prognostic factors and survival in patients with NSCLC $(N=404)$.

\begin{tabular}{|c|c|c|c|}
\hline Variable & Hazard ratio & $95 \%$ CI & p-value \\
\hline \multicolumn{4}{|l|}{ Age (years) } \\
\hline$<70$ & 1 & & \\
\hline$\geq 70$ & 1.703 & $1.380-2.102$ & $<0.0001$ \\
\hline \multicolumn{4}{|l|}{ Gender } \\
\hline Female & 1 & & \\
\hline Male & 1.273 & $1.023-1.585$ & 0.0306 \\
\hline \multicolumn{4}{|l|}{ Smoking status } \\
\hline Never & 1 & & \\
\hline Former & 1.263 & $0.939-1.699$ & 0.1228 \\
\hline Current & 1.410 & $1.119-1.777$ & 0.0035 \\
\hline \multicolumn{4}{|l|}{ ECOG performance status } \\
\hline$<2$ & 1 & & \\
\hline$\geq 2$ & 2.236 & $1.798-2.781$ & $<0.0001$ \\
\hline \multicolumn{4}{|l|}{ BMI $\left(\mathrm{kg} / \mathrm{m}^{2}\right)$} \\
\hline$<18.5$ & 1.430 & $1.002-2.043$ & 0.0490 \\
\hline $18.5-<25$ & 1 & & \\
\hline $25-<30$ & 0.969 & $0.541-1.738$ & 0.9166 \\
\hline$\geq 30$ & 0.949 & $0.722-1.247$ & 0.7068 \\
\hline missing & 4.013 & $2.838-5.674$ & $<0.0001$ \\
\hline \multicolumn{4}{|l|}{ Co-morbidity score } \\
\hline$<4$ & 1 & & \\
\hline $4-8$ & 1.479 & $1.162-1.883$ & 0.0015 \\
\hline$\geq 8$ & 1.873 & $1.366-2.568$ & $<0.0001$ \\
\hline \multicolumn{4}{|l|}{ Cancer stage } \\
\hline Less advanced & 1 & & \\
\hline Advanced & 2.375 & $1.575-3.582$ & $<0.0001$ \\
\hline \multicolumn{4}{|l|}{ Cancer treatment } \\
\hline Surgery & 1 & & \\
\hline Chemotherapy and/ or other supportive care & 4.877 & $2.408-9.877$ & $<0.0001$ \\
\hline None & 11.481 & $5.522-23.868$ & $<0.0001$ \\
\hline \multicolumn{4}{|l|}{ WBC counts $\left(10^{3} / \mu \mathrm{L}\right)$} \\
\hline$\leq 5.5$ & 0.789 & $0.586-1.063$ & 0.1192 \\
\hline $5.5-15.5$ & 1 & & \\
\hline$>15.5$ & 2.642 & $1.889-3.697$ & $<0.0001$ \\
\hline \multicolumn{4}{|l|}{ Neutrophil (\%) } \\
\hline $27-55$ & 1 & & \\
\hline$>55$ & 1.942 & $1.290-2.923$ & 0.0015 \\
\hline Missing & 1.897 & $1.105-3.257$ & 0.0203 \\
\hline \multicolumn{4}{|l|}{ Lymphocyte (\%) } \\
\hline$<16$ & 1.620 & $1.311-2.003$ & $<0.0001$ \\
\hline $16-46$ & 1 & & \\
\hline$>46$ & 0.240 & $0.077-0.752$ & 0.0143 \\
\hline
\end{tabular}




\begin{tabular}{|c|c|c|c|}
\hline \multicolumn{4}{|l|}{ Contunued } \\
\hline \multicolumn{4}{|c|}{ Hemoglobin (g/dL) } \\
\hline$<11.5$ & 1.908 & $1.482-2.455$ & $<0.0001$ \\
\hline $11.5-13.5$ & 1 & & \\
\hline$>13.5$ & 0.786 & $0.607-1.018$ & 0.0679 \\
\hline \multicolumn{4}{|c|}{ Platelet counts (Thou/ $\mu \mathrm{l})$} \\
\hline$<150$ & 0.803 & $0.634-1.016$ & 0.6628 \\
\hline $150-400$ & 1 & & \\
\hline$>400$ & 1.295 & $0.933-1.797$ & 0.1227 \\
\hline Missing & 0.913 & $0.605-1.377$ & 0.6628 \\
\hline \multicolumn{4}{|l|}{ Monocyte (\%) } \\
\hline$<4$ & 0.858 & $0.670-1.099$ & 0.2248 \\
\hline $4-11$ & 1 & & \\
\hline$>11$ & 1.310 & $0.861-1.993$ & 0.2080 \\
\hline \multicolumn{4}{|c|}{ Albumin (g/dl) } \\
\hline$<3.1$ & 3.728 & $2.598-5.350$ & $<0.0001$ \\
\hline $3.1-4.3$ & 1 & & \\
\hline$>4.3$ & 0.609 & $0.381-0.972$ & 0.0374 \\
\hline Missing & 1.070 & $0.850-1.346$ & 0.5657 \\
\hline \multicolumn{4}{|c|}{ Sodium (mmol/l) } \\
\hline$<136$ & 1.783 & $1.443-2.201$ & $<0.0001$ \\
\hline $136-147$ & 1 & & \\
\hline
\end{tabular}

Hgb level ( $<11.5 \mathrm{~g} / \mathrm{dL})$ had $5.4(95 \% \mathrm{CI}: 4.1$ - 7.2) survival months, compared with 12.2 months for patients with normal Hgb level and 7.5 months for patients with high Hgb level. For patients with low albumin level, the overall survival time was shorter $(2.4$ months; $95 \% \mathrm{CI}$ : 1.2 - 5.9), compared with those having normal and high albumin levels (12.4 months vs 22.0 months, respectively; $\mathrm{p}<0.0001$ ). Survival curvesfor these four markers are shown in Figures 1(a)-(d).

\subsection{Multivariate Analysis}

After performing the Pearson correlations, gender and smoking status were highly correlated $(r=0.68)$. Gender remained in the multivariate model for analysis because 1) it is a common characteristic for analysis; and 2) in an analysis of males only, smoking status was not a significant independent predictor for NSCLC (data not shown). After simultaneously adjusting for all potential prognostic factors (see Table 3), significantly lower survival rates were identifiedfor patients with older age $(\geq 70$ years), lower performance status, higher co-morbidity score $(>8)$, advanced lung cancer stage, cancer treatment rather than surgery, high WBC counts, low Hgblevels and low albumin levels. Correspondingly, similar results were found while performing a multivariable analysis stratified by cancer stage (data not shown). However, our data were insufficient to perform a similar analysis for patients with less advanced cancer stage, as only $7.1 \%$ patients with less advanced cancer diagnosis died within the study period.

\section{Discussion}

Our study demonstrated that older age, poor performance status, poor comorbid condition, advanced cancer stage, treatment other than surgery, high WBC counts, low Hgb levels and low albumin levels were significant prognostic factors forshorter NSCLC survival in multivariate analysis.

Tumor stage, performance status and weight loss at the time of diagnosis have been found tohave a negative impact on patient survival from NSCLC in previous research [34,35]. The present study confirmed that advanced cancer stage and poor performance status were prognostic factors for NSCLC survival. However, low BMI $\left(<18.5 \mathrm{~kg} / \mathrm{m}^{2}\right)$ was a significant prognostic factor in univariate analysis but not in multivariate analysis in our study. This may due to the fact that BMI data were missing in $10 \%$ of cases. We observed that patients with missing BMI all died within the study follow-up period, indicating that patients with unavailable BMI data during hospitalization were more likely to be severely ill with relatively higher mortality rate. In addition, individuals with missing BMI data tended to be older, with advanced cancer stage, and have poor performance status. 


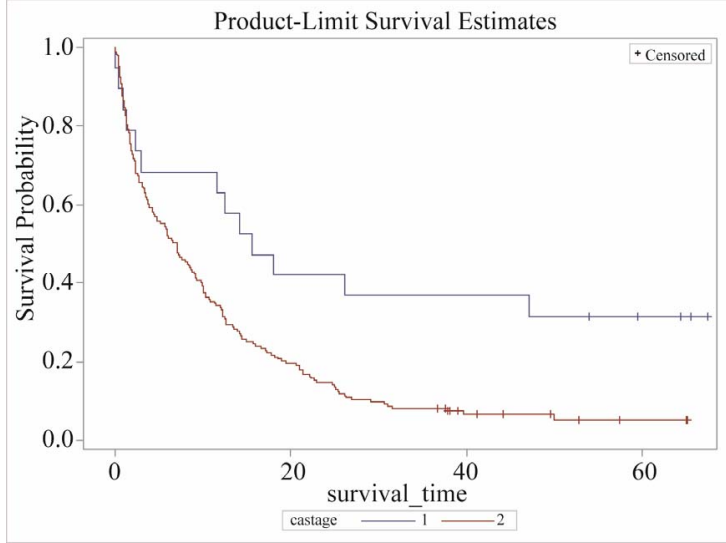

(a)

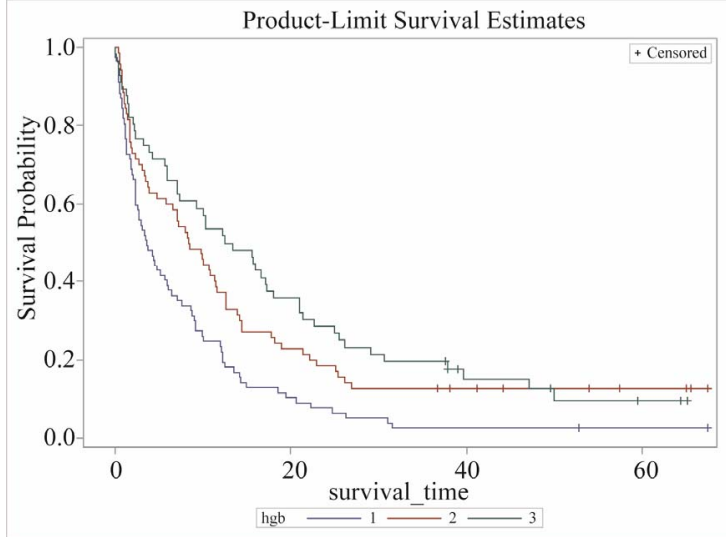

(c)

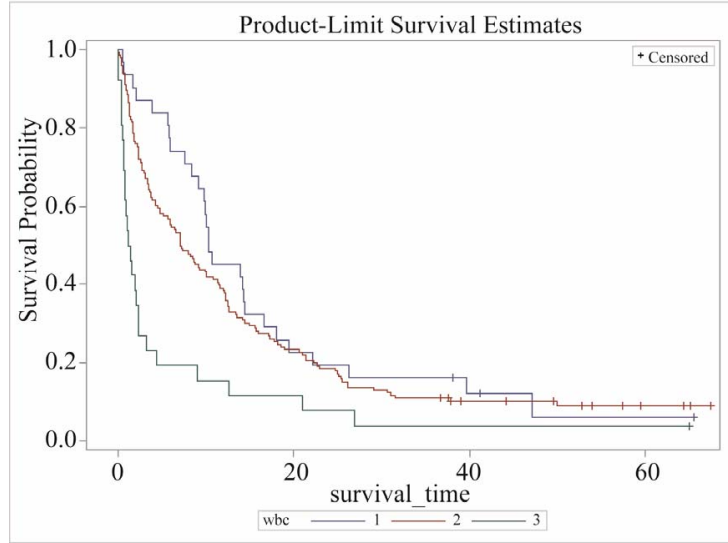

(b)

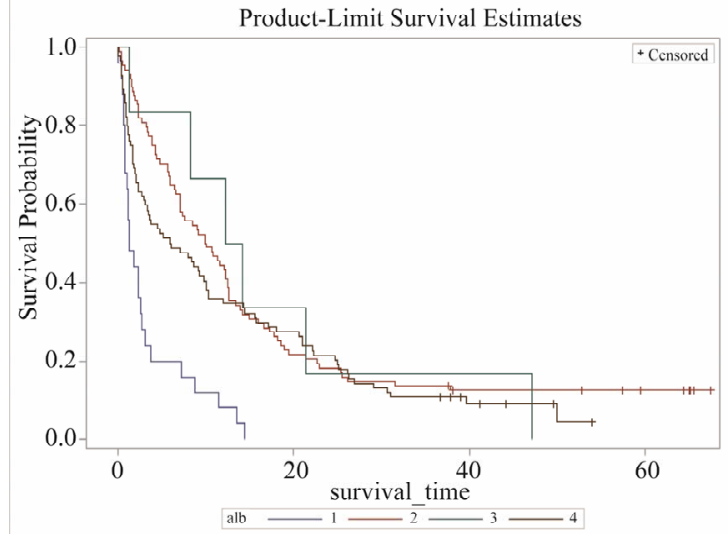

(d)

Figure 1. NSCLC survival curve by cancer staging and laboratory biomarkers $(N=404)$. (a) Survival curves by cancer stage: 1 for less advanced stage, 2 for advanced stage $(p<0.0001)$; (b) Survival curves by WBC counts: 1 for $\leq 5.5 \times 10^{3} / \mu \mathrm{L}, 2$ for $5.5 \times 10^{3} / \mu \mathrm{L}-15.5 \times 10^{3} / \mu \mathrm{L}, 3$ for $>15.5 \times 10^{3} / \mu \mathrm{L}(\mathrm{p}<0.0001)$; (c) Survival curves by hemoglobin (Hgb) level: 1 for $\leq 11.5$ $\mathrm{g} / \mathrm{dL}, 2$ for $11.5 \mathrm{~g} / \mathrm{dL}-13.5 \mathrm{~g} / \mathrm{dL}, 3$ for $>13.5 \mathrm{~g} / \mathrm{dL}$ ( $\mathrm{p}<\mathbf{0 . 0 0 0 1})$; (d) Survival curves by serum albumin (alb) level: 1 for $\leq 3.1$ $\mathrm{g} / \mathrm{dL}, 2$ for $3.1 \mathrm{~g} / \mathrm{dL}-4.3 \mathrm{~g} / \mathrm{dL}, 3$ for $>4.3 \mathrm{~g} / \mathrm{dL}, 4$ for missing value $(\mathrm{p}<0.0001)$.

Table 3. Multivariate analyses of key prognostic factors and survival in patients with NSCLC $(\mathrm{N}=404)$.

\begin{tabular}{|c|c|c|c|}
\hline Variable & Hazard ratio & $95 \% \mathrm{CI}$ & p-value \\
\hline \multicolumn{4}{|l|}{ Age } \\
\hline$<70$ & 1 & & \\
\hline$\geq 70$ & 1.445 & $1.147-1.819$ & 0.0017 \\
\hline \multicolumn{4}{|l|}{ Gender } \\
\hline Female & 1 & & \\
\hline Male & 1.183 & $0.936-1.494$ & 0.1597 \\
\hline \multicolumn{4}{|l|}{ BMI $\left(\mathrm{kg} / \mathrm{m}^{2}\right)$} \\
\hline$<18.5$ & 0.980 & $0.658-1.460$ & 0.9207 \\
\hline $18.5-<25$ & 1 & & \\
\hline $25-<30$ & 0.998 & $0.750-1.329$ & 0.9898 \\
\hline$\geq 30$ & 1.129 & $0.619-2.065$ & 0.6924 \\
\hline missing & 2.269 & $1.514-3.399$ & $<0.0001$ \\
\hline
\end{tabular}




\section{Contunued}

\begin{tabular}{|c|c|c|c|}
\hline \multicolumn{4}{|l|}{ ECOG Performance status } \\
\hline$<2$ & 1 & & \\
\hline$\geq 2$ & 1.506 & $1.167-1.943$ & 0.0017 \\
\hline \multicolumn{4}{|l|}{ Co-morbidity score } \\
\hline$<4$ & 1 & & \\
\hline $4-8$ & 1.354 & $1.023-1.791$ & 0.0340 \\
\hline$\geq 8$ & 1.557 & $1.103-2.199$ & 0.0118 \\
\hline \multicolumn{4}{|l|}{ Cancer stage } \\
\hline Less advanced & 1 & & \\
\hline Advanced & 1.818 & $1.153-2.867$ & 0.0101 \\
\hline \multicolumn{4}{|l|}{ Cancer treatment } \\
\hline Surgery & 1 & & \\
\hline Chemotherapy and/ or other supportive care & 2.513 & $1.202-5.257$ & 0.0144 \\
\hline None & 5.704 & $2.665-12.211$ & $<0.0001$ \\
\hline \multicolumn{4}{|l|}{ WBC counts $\left(10^{3} / \mu \mathrm{L}\right)$} \\
\hline$\leq 5.5$ & 0.798 & $0.577-1.104$ & 0.1724 \\
\hline $5.5-15.5$ & 1 & & \\
\hline$>15.5$ & 1.798 & $1.225-2.639$ & 0.0027 \\
\hline \multicolumn{4}{|l|}{ Neutrophil (\%) } \\
\hline $27-55$ & 1 & & \\
\hline$>55$ & 1.308 & $0.826-2.070$ & 0.2521 \\
\hline Missing & 1.650 & $0.891-3.055$ & 0.1112 \\
\hline \multicolumn{4}{|l|}{ Lymphocyte (\%) } \\
\hline$<16$ & 0.931 & $0.705-1.230$ & 0.6157 \\
\hline $16-46$ & 1 & & \\
\hline$>46$ & 0.475 & $0.139-1.622$ & 0.2350 \\
\hline \multicolumn{4}{|l|}{ Hemoglobin (g/dL) } \\
\hline$<11.5$ & 1.437 & $1.085-1.903$ & 0.0115 \\
\hline $11.5-13.5$ & 1 & & \\
\hline$>13.5$ & 0.901 & $0.686-1.183$ & 0.4522 \\
\hline \multicolumn{4}{|l|}{ Albumin (g/dl) } \\
\hline$<3.1$ & 2.149 & $1.376-3.052$ & 0.0004 \\
\hline $3.1-4.3$ & 1 & & \\
\hline$>4.3$ & 0.943 & $0.580-1.534$ & 0.8131 \\
\hline Missing & 1.279 & $1.006-1.625$ & 0.0443 \\
\hline \multicolumn{4}{|l|}{ Sodium (mmol/l) } \\
\hline$<136$ & 1.141 & $0.895-1.454$ & 0.2875 \\
\hline $136-147$ & 1 & & \\
\hline
\end{tabular}

Comorbidity condition was also observed as a predictor of lung cancer survival. Previous findings on comorbidity are inconsistent. Janssen et al. reported no independent prognostic effect of comorbidity condition for patients with non-small cell lung cancer [36]. However, in line with our study, Wang and colleagues revealed that patients with CCI score $\geq 2$ had higher perioperative mortality and death from NSCLC compared with patients with CCI score $<2$ [37]. Firat et al. and Moro-Sibilot et $a l$. also studied the significance of comorbidity scores in stage I NSCLC patients and found it to be a significant prognostic impact [38,39].

Our study confirmed that elevated WBC counts were significantly associated with poor prognosis among 
NSCLC patients, which aligned with most previous observations [13]. In a nationally representative adult cohort study, WBC counts werefound to be positively and independently associated with cancer mortality after adjusting for age, gender and race [40]. In that study, inflammation was associated with WBC counts as well. $\mathrm{WBC}$ as a marker of inflammatory level reflects either a greater burden of tumor cells within the bone marrow, a possible concomitant subclinical infection, or the effect of a yet undescribed chemokine or cytokine secreted by the tumor into the circulation. Stromal tissues of tumors contain large numbers of WBC counts, and the inflammatory cell number and their cytokine production correlate with tumor severity and prognosis [41-44].

We also identified the relationship of both low $\mathrm{Hgb}$ and serum albumin levels with poor survival as reported in other studies $[12,13,23,24,45,46]$. Takugawa et al. stated low Hgb level correlated with overall survival among patients with NSCLC [47]. Similar findings were reported in Albain's study [48]. For serum albumin level, Phillips reported a marked increase in mortality rate with decreasing serum albumin concentrations among cancer and cardiovascular patients [49]. Another study found an approximate $25 \%$ reduction in cancer mortality among middle aged men with a one standard deviation increase in serum albumin [50]. Similar to the elevated WBC counts, low $\mathrm{Hgb}$ and serum albumin levels also play an influential role in body inflammation. Serum albumin is a negative acute phase protein; its concentration in the blood is reduced in response to inflammation [51]. Hypoalbuminemia is the result of the combined effects of inflammation and inadequate protein and caloric intake in patients with chronic disease and cancer. Inflammation and malnutrition both reduce albumin concentration by decreasing its rate of synthesis, while inflammation alone is associated with a greater fractional catabolic rate (FCR) and, when extreme, increased transfer of albumin out of the vascular compartment [50]. This study is the first to assess clinical prognostic factors in a Taiwanese population, although several other Asian research articles haveidentified the traditional factors for lung cancer survival including old age, no surgery treatment, performance status, and advanced lung cancer stage $[28,52,53]$.

The findings of this study should be considered in the context of its strengths and limitations. Study strengths include the fact that 1) all lung cancer cases were newly diagnosed which ruled out impact on patients' outcomes by possible cancer pretreatment that patients may have received. In addition, 2) the outcome measure (death yes/no) was tracked up to 3 - 5 years in order to predict long term prognosis for NSCLC; and 3) we were able to collect and adjust for most potential prognostic factors such as smoking status, BMI, and performance status.

However, the present study was also limited in several respects. Using data derived from retrospective hospital records review, we found that routinely examined laboratory item such as albumin level was not available for every individual during the hospital stay. These missing data limited the ability of our study to conduct a complete data analysis. In addition, the study uses a sample from a Taiwanese patient populationmost of whom reside in a rural area, which may limit the generalizability of study findings of NSCLC survival outcomes to other populations.

\section{Conclusion}

This study contributes to research on overall NSCLC survival by concurrently identifying significant laboratory biomarkers for survival, including WBC counts, Hgb level, and serum albumin level. Additionally we confirmed the widely accepted prognostic factors of lung cancer survival such as old age, advanced cancer, severe comorbidity, performance status, and lack of surgery treatment. Because these identified biomarkers are routinelychecked during hospital admissions, the findings of this study could help in the early identification of patients atrisk of shorter NSCLC survival to provide better clinical patients care. Moreover, to extend and confirm the current study findings, future studies shouldapply more comprehensive prognostic assessments, conduct longer follow-ups, and study additional ethnic populations.

\section{Acknowledgements}

This study was supported by the Faculty Research Grant (TCCT-981A11), Buddhist Tzu Chi College of Technology, to L. J. Chang. We would like to express our gratitude to Tzu Chi General Hospital Dalin Branch and Cancer Tumor Center for their efforts and assistance for data collection.

\section{REFERENCES}

[1] A. Jemal, R. Siegel, E. Ward, Y. Hao, J. Xu and M. J. Thun, "Cancer Statistics, 2009," CA-A Cancer Journal for Clinicians, Vol. 59, No. 4, 2009, pp. 225-249. doi: $10.3322 /$ caac. 20006

[2] A. Jemal, F. Bray, M. M. Center, J. Ferlay, E. Ward and D. Forman, "Global Cancer Statistics," CA-A Cancer Journal for Clinicians, Vol. 61, No. 6, 2011, pp. 69-90. doi:10.3322/caac. 20107

[3] C. L. B. Ott, N. Ratna, R. Prayag, Z. Nugent, K. Badiani and S. Navaratnam, "Survival and Treatment Patterns in Elderly Patients with Advanced Non-Small-Cell Lung Cancer in Manitoba," Current Oncology, Vol. 18, No. 5, 2011, pp. e238-e242.

[4] E. Quoix, V. Westeel, G. Zalcman and B. Milleron, "Chemotherapy in Elderly Patients with Advanced NonSmall Cell Lung Cancer," Lung Cancer, Vol. 74, No. 3, 
2011, pp. 364-368. doi:10.1016/j.lungcan.2011.06.006

[5] W. D. Wei, Z. S. Wen, X. D. Su, P. Lin, T. H. Rong and L. K. Chen, "Multivariate Survival Analysis of $899 \mathrm{~Pa}-$ tients with Non-Small Cell Lung Cancer after Complete Resection," Cancer, Vol. 26, No. 11, 2007, pp. 12311236.

[6] K. Hotta, Y. Fujiwara, K. Kiura, N. Takigawa, M. Tabata, H. Ueoka and M. Tanimoto, "Relationship between Response and Survival in More than 50,000 Patients with Advanced Non-Small Cell Lung Cancer Treated with Systemic Chemotherapy in 143 Phase III Trials," Journal of Thoracic Oncology, Vol. 2, 2007, pp. 402-407. doi:10.1097/01.JTO.0000268673.95119.c7

[7] J. L. Port, M. S. Kent, R. J. Korst, D. Libby, M. Pasmantier and N. K. Altorki, "Tumor Size Predicts Survival within Stage IA Non-Small Cell Lung Cancer," Chest, Vol. 124, No. 5, 2003, pp. 1828-1833. doi:10.1378/chest.124.5.1828

[8] E. F. Patz Jr., S. Rossi, D. H. Harpole Jr., J. E. Herndon and P. C. Goodman, "Correlation of Tumor Size and Survival in Patients with Stage IA Non-Small Cell Lung Cancer," Chest, Vol. 117, 2000, pp. 1568-1571. doi:10.1378/chest.117.6.1568

[9] L. M. Forrest, D. C. McMillan, C. S. McArdle, W. J. Angerson, K. Dagg and H. R. Scott, "A Prospective Longitudinal Study of Performance Status, an Inflammation-Based Score (GPS) and Survival in Patients with Inoperable Non-Small-Cell Lung Cancer," British Journal of Cancer, Vol. 92, 2005, pp. 1834-1836. doi:10.1038/sj.bjc.6602591

[10] H. R. Scott, D. C. McMillan, L. M. Forrest, D. J. Brown, C. S. McArdle and R. Milroy, "The Systemic Inflammatory Response, Weight Loss, Performance Status and Survival in Patients with Inoperable Non-Small Cell Lung Cancer," British Journal of Cancer, Vol. 87, No. 3, 2002, pp. 264-267. doi:10.1038/sj.bjc.6600466

[11] M. K. Mohamed, S. Ramalingam, Y. Lin, W. Gooding and C. P. Belani, "Skin Rash and Good Performance Status Predict Improved Survival with Gefitinib in Patients with Advanced Non-Small Cell Lung Cancer," Annals of Oncology, Vol. 16, No. 5, 2005, pp. 780-785. doi:10.1093/annonc/mdi157

[12] T. Maeda, H. Ueoka, M. Tabata, K. Kiura, T. Shibayama, K. Gemba, N. Takigawa, A. Hiraki, H. Katayama and M. Harada, "Prognostic Factors in Advanced Non-Small Cell Lung Cancer: Elevated Serum Levels of Neuron Specific Enolase Indicate Poor Prognosis," Japanese Journal of Clinical Oncology, Vol. 30, No. 12, 2000, pp. 534-541. doi:10.1093/jjco/hyd139

[13] S. J. Mandrekar, S. E. Schild, S. L. Hillman, K. L. Allen, R. S. Marks, J. A. Mailliard, J. E. Krook, A. W. Maksymiuk, K. Chansky, K. Kelly, A. A. Adjei and J. R. Jett, "A Prognostic Model for Advanced Stage Nonsmall Cell Lung Cancer. Pooled Analysis of North Central Cancer Treatment Group Trials," Cancer, Vol. 107, No. 4, 2006, pp. 781-792. doi:10.1002/cncr.22049

[14] C. W. Francis, A. Blinc, S. Lee and C. Cox, "Ultrasound Accelerates Transport of Recombinant Tissue Plasminogen Activator into Clots," Ultrasound in Medicine \& Bi- ology, Vol. 21, No. 3, 1995, pp. 419-424. doi:10.1016/0301-5629(94)00119-X

[15] L. R. Zacharski, M. Z. Wojtukiewicz, V. Costantini, D. L. Ornstein and V. A. Memoli, "Pathways of Coagulation/Fibrinolysis Activation in Malignancy," Semin Thromb Hemost, Vol. 18, No. 1, 1992, pp. 104-116. doi:10.1055/s-2007-1002415

[16] K. R. Meehan, L. R. Zacharski, T. E. Moritz and F. R. Rickles, "Pretreatment Fibrinogen Levels Are Associated with Response to Chemotherapy in Patients with Small Cell Carcinoma of the Lung: Department of Veterans Affairs Cooperative Study 188," American Journal of Hematology, Vol. 49, 1995, pp. 143-148. doi:10.1002/ajh.2830490208

[17] O. Taguchi, E. C. Gabazza, H. Yasui, T. Kobayashi, M. Yoshida and H. Kobayashi, "Prognostic Significance of Plasma D-Dimer Levels in Patients with Lung Cancer," Thorax, Vol. 52, No. 6, 1997, pp. 563-565. doi:10.1136/thx.52.6.563

[18] M. Z. Wojtukiewicz, L. R. Zacharski, T. E. Moritz, K. Hur, R. L. Edwards and F. R. Rickles, "Prognostic Significance of Blood Coagulation Tests in Carcinoma of the Lung and Colon," Blood Coagul Fibrinolysis, Vol. 3, No. 4, 1992, pp. 429-437.

[19] D. Ferrigno, G. Buccheri and I. Ricca, "Prognostic Significance of Blood Coagulation Tests in Lung Cancer," European Respiratory Journal, Vol. 17, No. 4, 2001, pp. 667-673. doi:10.1183/09031936.01.17406670

[20] M. Paesmans, J. P. Sculier, P. Libert, G. Bureau, G. Dabouis, J. Thiriaux, J. Michel, O. Van Cutsem, R. Sergysels, P. Momme, et al., "Prognostic Factors for Survival in Advanced Non-Small-Cell Lung Cancer: Univariate and Multivariate Analyses Including Recursive Partitioning and Amalgamation Algorithms in $1052 \mathrm{~Pa}-$ tients. The European Lung Cancer Working Party," Journal of Clinical Oncology, Vol. 13, No. 5, 1995, pp. 1221-1230.

[21] J. S. Paddison, J. S. Temel, G. L. Fricchione and W. F. Pirl, "Using the Differential from Complete Blood Counts as a Biomarker of Fatigue in Advanced Non-Small-Cell Lung Cancer: An Exploratory Analysis," Palliat Support Care, Vol. 7, No. 2, 2009, pp. 213-217. doi:10.1017/S1478951509000273

[22] D. Ferrigno and G. Buccheri, "Hematologic Counts and Clinical Correlates in 1201 Newly Diagnosed Lung Cancer Patients," Monaldi Archives for Chest Disease, Vol. 59, No. 3, 2003, pp. 193-198.

[23] T. Win, L. Sharples, A. M. Groves, A. J. Ritchie, F. C. Wells and C. M. Laroche, "Predicting Survival in Potentially Curable Lung Cancer Patients," Lung, Vol. 186, No. 2, 2008, pp. 97-102. doi:10.1007/s00408-007-9067-1

[24] F. Tas, A. Aydiner, E. Topuz, H. Camlica, P. Saip and Y. Eralp, "Factors Influencing the Distribution of Metastases and Survival in Extensive Disease Small Cell Lung Cancer," Acta Oncologica, Vol. 38, No. 8, 1999, pp. 10111015. doi:10.1080/028418699432275

[25] S. L. Vanhees, R. Paridaens and J. F. Vansteenkiste, "Syndrome of Inappropriate Antidiuretic Hormone Associated with Chemotherapy-Induced Tumour Lysis in 
Small-Cell Lung Cancer: Case Report and Literature Review," Annals of Oncology, Vol. 11, 2000, pp. 1061-1065. doi:10.1023/A:1008369932384

[26] O. Hansen, P. Sorensen and K. H. Hansen, "The Occurrence of Hyponatremia in SCLC and the Influence on Prognosis: A Retrospective Study of 453 Patients Treated in a single Institution in a 10-Year Period," Lung Cancer, Vol. 68, No. 1, 2010, pp. 111-114. doi:10.1016/j.lungcan.2009.05.015

[27] N. S. Rawson and J. Peto, "An Overview of Prognostic Factors in Small Cell Lung Cancer. A Report from the Subcommittee for the Management of Lung Cancer of the United Kingdom Coordinating Committee on Cancer Research," British Journal of Cancer, Vol. 61, No. 4, 1990, pp. 597-604. doi:10.1038/bjc.1990.133

[28] J. Luo, Y. J. Chen and L. J. Chang, "Fasting Blood Glucose Level and Prognosis in Non-Small Cell Lung Cancer (NSCLC) Patients," Lung Cancer, Vol. 76, No. 2, 2011, pp. 242-247. doi:10.1016/j.lungcan.2011.10.019

[29] M. M. Oken, R. H. Creech, D. C. Tormey, J. Horton, T. E. Davis, E. T. McFadden and P. P. Carbone, "Toxicity and Response Criteria of the Eastern Cooperative Oncology Group," American Journal of Clinical Oncology, Vol. 5, No. 6, 1982, pp. 649-655. doi:10.1097/00000421-198212000-00014

[30] M. E. Charlson, P. Pompei, K. L. Ales and C. R. MacKenzie, "A New Method of Classifying Prognostic Comorbidity in Longitudinal Studies: Development and Validation," Journal of Chronic Diseases, Vol. 40, No. 5, 1987, pp. 373-383. doi:10.1016/0021-9681(87)90171-8

[31] O. Birim, A. P. Kappetein and A. J. Bogers, "Charlson Comorbidity Index as a Predictor of Long-Term Outcome after Surgery for Nonsmall Cell Lung Cancer," European Journal Cardio-Thoracic Surgery, Vol. 28, No. 5, 2005, pp. 759-762. doi:10.1016/j.ejcts.2005.06.046

[32] J. V. Corbett, "Laboratory Tests and Diagnostic Procedures with Nursing Diagnoses," Pearson/Prentice Hall, Upper Saddle River, 2004.

[33] D. R. Cox and D. Oakes, "Analysis of Survival Data," Chapman and Hall, London, 1984.

[34] S. Leij-Halfwerk, P. C. Dagnelie, J. W. van Den Berg, J. D. Wattimena, C. H. Hordijk-Luijk and J. P. Wilson, "Weight Loss and Elevated Gluconeogenesis from Alanine in Lung Cancer Patients," American Journal of Clinical Nutrition, Vol. 71, 2000, pp. 583-589.

[35] H. Wertzel, H. Siebert, W. Lange, L. Swoboda, E. Graf and J. Hasse, "Results after Surgery in Stage-I Bronchogenic Carcinoma," Journal of Thoracic and Cardiovascular Surgery, Vol. 46, 1998, pp. 365-369. doi:10.1055/s-2007-1010255

[36] R. R. Jennens, G. G. Giles and R. M. Fox, "Increasing Under Representation of Elderly Patients with Advanced Colorectal or Non-Small-Cell Lung Cancer in Chemotherapy Trials," Internal Medicine Journal, Vol. 36, 2006, pp. 216-220. doi:10.1111/j.1445-5994.2006.01033.X

[37] C. Y. Wang, Y. S. Lin, C. Tzao, H. C. Lee, M. H. Huang, W. H. Hsu and H. S. Hsu, "Comparison of Charlson Comorbidity Index And Kaplan-Feinstein Index in Patients with Stage I Lung Cancer after Surgical Resection," European Journal Cardio-Thoracic Surgery, Vol. 32, No. 6, 2007, pp. 877-881. doi:10.1016/j.ejcts.2007.09.008

[38] S. Firat, M. Bousamra, E. Gore and R. W. Byhardt, "Comorbidity and KPS Are Independent Prognostic Factors in Stage I Non-Small-Cell Lung Cancer," International Journal of Radiation Oncology*Biology*Physics, Vol. 52, 2002, pp. 1047-1057.

[39] D. Moro-Sibilot, A. Aubert, S. Diab, S. Lantuejoul, P. Fourneret, E. Brambilla, C. Brambilla and P. Y. Brichon, "Comorbidities and Charlson Score in Resected Stage I nonsmall Cell Lung Cancer," European Respiratory Journal, Vol. 26, No. 3, 2005, pp. 480-486. doi:10.1183/09031936.05.00146004

[40] A. Shankar, J. J. Wang, E. Rochtchina, M. C. Yu, R. Kefford and P. Mitchell, "Association between Circulating White Blood Cell Count and Cancer Mortality: A Population-Based Cohort Study," Archives of Internal Medicine, Vol. 166, 2006, pp. 188-194. doi:10.1001/archinte.166.2.188

[41] L. M. Coussens and Z. Werb, "Inflammation and Cancer," Nature, Vol. 420, No. 6917, 2002, pp. 860-867. doi:10.1038/nature 01322

[42] F. Balkwill, "Cancer and the Chemokine Network," Nature Reviews Cancer, Vol. 4, 2004, pp. 540-550. doi: $10.1038 / \mathrm{nrc1388}$

[43] F. Balkwill and L. M. Coussens, "Cancer: An Inflammatory Link," Nature, Vol. 431, No. 7007, 2004, pp. 405406. doi:10.1038/431405a

[44] E. Pikarsky, R. M. Porat, I. Stein, R. Abramovitch, S. Amit, S. Kasem, E. Gutkovich-Pyest, S. Urieli-Shoval, E. Galun and Y. Ben-Neriah, "NF-kappaB Functions as a Tumour Promoter in Inflammation-Associated Cancer," Nature, Vol. 431, No. 7007, 2004, pp. 461-466. doi: $10.1038 /$ nature 02924

[45] M. D. Brundage, D. Davies and W. J. Mackillop, "Prognostic Factors in Non-Small Cell Lung Cancer: A Decade of Progress," Chest, Vol. 122, No. 3, 2002, pp. 1037-1057. doi:10.1378/chest.122.3.1037

[46] S. Sugiura, Y. Ando, H. Minami, M. Ando, S. Sakai and K. Shimokata, "Prognostic Value of Pleural Effusion in Patients with Non-Small Cell Lung Cancer," Clinical Cancer Research, Vol. 3, 1997, pp. 47-50.

[47] N. Takigawa, Y. Segawa, M. Okahara, Y. Maeda, I. Takata, M. Kataoka and M. Fujii, "Prognostic Factors for Patients with Advanced Non-Small Cell Lung Cancer: Univariate and Multivariate Analyses Including Recursive Partitioning and Amalgamation," Lung Cancer, Vol. 15, No. 1, 1996, pp. 67-77. doi:10.1016/0169-5002(96)00571-5

[48] K. S. Albain, J. J. Crowley, M. LeBlanc and R. B. Livingston, "Survival Determinants in Extensive-Stage Non-Small-Cell Lung Cancer: The Southwest Oncology Group Experience," Journal of Clinical Oncology, Vol. 9, No. 9, 1991, pp. 1618-1626.

[49] A. Phillips, A. G. Shaper and P. H. Whincup, "Association between Serum Albumin and Mortality from Cardiovascular Disease, Cancer, and Other Causes," Lancet, 
Vol. 2, 1989, pp. 1434-1436. doi:10.1016/S0140-6736(89)92042-4

[50] B. R. Don and G. Kaysen, "Serum Albumin: Relationship to Inflammation and Nutrition," Seminars in Dialysis, Vol. 17, No. 6, 2004, pp. 432-437. doi:10.1111/j.0894-0959.2004.17603.x

[51] B. L. Sprague, A. Trentham-Dietz, B. E. Klein, R. Klein, K. J. Cruickshanks, K. E. Lee and J. M. Hampton, "Physical Activity, White Blood Cell Count, and Lung Cancer Risk in a Prospective Cohort Study," Cancer Epidemiology, Biomarkers \& Prevention, Vol. 17, No. 10,
2008, pp. 2714-2722.

doi:10.1158/1055-9965.EPI-08-0042

[52] Y. H. Li, S. H. Shieh and C. Y. Chen, "The Influence of Health Behaviors on Survival in Lung Cancer Patients in Taiwan," Japanese Journal of Clinical Oncology, Vol. 41, No. 3, 2011, pp. 365-372. doi:10.1093/jjco/hyq188

[53] T. A. Chiang, P. H. Chen, P. F. Wu, T. N. Wang, P. Y. Chang, A. M. Ko, M. S. Huang and Y. C. Ko, "Important Prognostic Factors for the Long-Term Survival of Lung Cancer Subjects in Taiwan," BMC Cancer, Vol. 8, No. 324, 2008. 